\title{
Intrinsic Basicity of Oligomeric Peptides that Contain Glycine, Alanine, and Valine-The Effects of the Alkyl Side Chain on Proton Transfer Reactions
}

\author{
Jiangyue Wu and Carlito B. Lebrilla \\ Department of Chemistry, University of California, Davis, California, USA
}

\begin{abstract}
The gas-phase basicities of oligomers of alanine and valine have been determined by bracketing measurements in an external source Fourier transform mass spectrometer. The results are compared to the oligomers of glycine, which were reported in an earlier publication, to observe the effect of the alkyl group and the increasing gas-phase basicity of the monomer units on the rates of proton transfer reactions. Molecular orbital calculations were performed on protonated triglycine and trialanine to determine how the alkyl groups affect intramolecular interactions. The results show that a high degree of ordering of the carbonyl groups is present in the protonated species. The carbonyl groups in turn order the side chain alkyl groups and decrease the rates of proton transfer reactions in, for example, the oligomers of valine. (J Am Soc Mass Spectrom 1995, 6, 91-101)
\end{abstract}

$\mathrm{T}$ The interactions of ions with peptides provide clues concerning the intramolecular interactions found in proteins. It long has been known that ions can strongly alter the thermodynamic and physical properties of peptides in solutions [1,2]. Denaturation of proteins is related to salt activity and has been studied intensively [1-3]. Gas-phase protonation provides a method for investigation of the inherent behavior of peptides in the presence of a single ion; it also can provide information on intramolecular hydrogen bonding interactions, which are important factors in the tertiary and quaternary structures of proteins.

Gas-phase basicity (GB) and intramolecular hydrogen bonding are integrally linked in isolated organic molecules. The first gas-phase basicities of amino acids were reported nearly 14 years ago by Locke et al. [4, 5], Lias et al. [6], and Moet-Ner et al. [7]. Intramolecular interactions, particularly hydrogen bonding, can greatly increase the basicity of an amino acid. For example, the difference in GB between valine with one amino group and lysine with two amino groups is about $20 \mathrm{kcal} / \mathrm{mol}[4,6,8-12]$. Gas-phase basicity values, both absolute and relative, and proton affinity values have been reported for the 20 naturally occurring $\alpha$-amino acids $[4,8-12]$. The GB values of peptides are recent and deal only with small numbers of

Address reprint requests to Professor Carlito B. Lebrilla, Department of Chemistry, University of California, Davis, California 95616. residues. For example, the gas-phase basicities of glycine oligomers [13-15] and some dipeptides [16] have been reported.

Bracketing techniques have allowed us to determine the gas-phase basicity values of oligomers of glycine [14]. We found that an increase in the length of the peptide chains increases the basicity to some degree. With glycine oligomers, there is a significant increase from the amino acid to the dipeptide (a $5.3-\mathrm{kcal} / \mathrm{mol}$ increase), a slight increase from the di- to the tripeptide $(1.1 \mathrm{kcal} / \mathrm{mol})$, and no further increase as the peptide chain is lengthened to the five amino acid residue. From results of semiempirical molecular orbital calculations (AM1), we found that the increase in basicity as a function of chain length is due to increased intramolecular hydrogen bonding interactions. Interestingly, a similar trend in the opposite direction is observed in solution. The $p K_{n 2}$ values of glycine oligomers, which are associated with deprotonation of the terminal amine (Reaction 1), decrease (the compounds become less basic) as the length of the chain increases (Figure 1) [17]. The opposite trend in aqueous solution is due to the effects of solvation. The smaller amino acid allows close contact between the protonated amine and the deprotonated carboxylate groups (the compounds are zwitterionic in solution). As the two groups are moved further away in the peptide, both are stabilized by solvation, which decreases the effects of intramolecular interactions. In both solution and gas-phase, however, intramolecular 


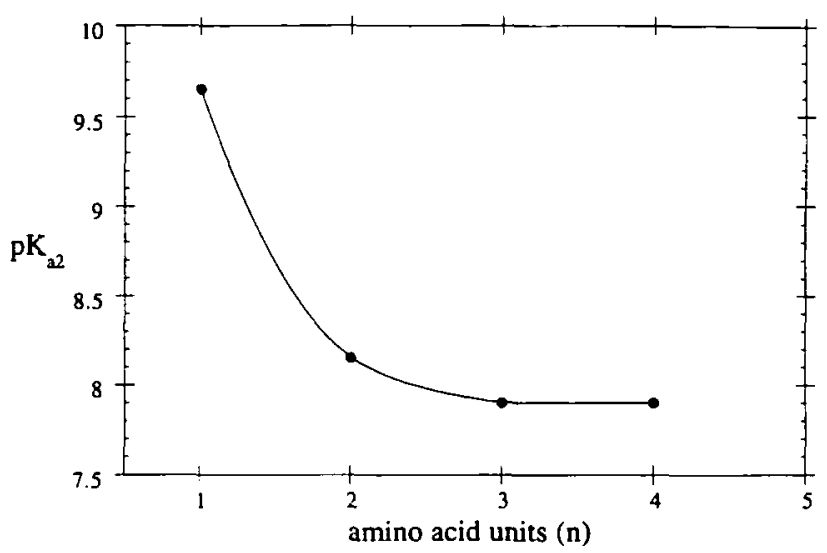

Figure 1. The plot of $p K_{a 2}$ versus $n$ of glycine oligomers in aqueous solution. The acidity increases as the length of the peptide chain increases. Values are taken from [17].

interaction is an important factor in the basicity of the compound.

$$
\mathrm{H}_{3} \mathrm{~N}^{+} \stackrel{\mathrm{O}}{\mathrm{O}^{-}}(\mathrm{aq}) \rightleftharpoons \mathrm{H}^{+}(\mathrm{aq})
$$

Glycine is unique because it is the least basic amino acid and it does not contain a side chain group. An alkyl side chain is capable of introducing two major effects. It can increase the GB of the amino acid. For example, the methyl group of alanine makes it 3-7 $\mathrm{kcal} / \mathrm{mol}$ more basic than glycine [6]. This trend continues to some extent in amino acids with larger alkyl groups such as valine and leucine. In peptides, however, a large alkyl group also may produce steric interactions that can interfere with intramolecular hydrogen bonding. This will specifically affect the GB of the peptide because these interactions play a major role in the stabilization of the protonated structures. Also, it is difficult to predict whether or not the gasphase behavior of the glycine oligomers will be duplicated in oligomers of amino acids that contain alkyl side chains. The effects of increased amino acid basicity and increased steric interactions can be deduced from trends in the GB of the peptide.

In this report, we present the gas-phase basicities of alanine and valine oligomers. Both amino acids have greater GB than glycine because of the presence of the methyl and isopropyl groups, respectively, as side chains. The alkyl groups can produce steric interactions when incorporated into the peptide. Experimental results are compared to theoretical calculations performed with AM1 for triglycine and trialanine.

\section{Experimental}

Details of the experiments and the instrumentation have been published in earlier reports $[14,18,19]$. The instrument was built in this laboratory and is controlled by an Omega data system (Ionspec Corp., Irvine, CA); it is equipped with a $3-T$ superconducting magnet. Ions are produced by liquid secondary ionization mass spectrometry with a $\mathrm{Cs}^{+}$primary beam. The protonated peptides are transported from the source to the analyzer cell, by using a single stage quadrupole rod assembly, where they are trapped for the length of the reaction period. Proton transfer reactions with a background pressure of a reference base (typically between $1 \times 10^{-8}$ and $3 \times 10^{-8}$ torr) occur during this period. Pressure is determined by an empirical method by using relative ion gauge sensitivities [20]. The relative sensitivities $\left(R_{x}\right)$ of different gases were obtained from the empirical equation

$$
R_{x}=0.36 \alpha+0.30
$$

where $\alpha$ is the polarizability, which can be obtained either from the literature or from the empirical formula [21]

$$
\alpha=\left(\frac{4}{N}\right)\left(\sum \tau_{\mathrm{A}}\right)^{2}
$$

where $\tau_{A}$ is the atomic hybrid component for each atom $\mathrm{A}$ in a given state of hybridization and $N$ is the total number of electrons. The average error in $\alpha$ determined by this method is less than $3 \%$ as confirmed by the calculation of compounds with known polarizability. The error in $\mathrm{R}_{x}$ is less than $20 \%$ as confirmed by the calculation of rate constants of known reactions.

All compounds used in the bracketing measurements were obtained from commercial sources and were used without further purification. Reference bases were degassed by using several (at least three) freeze-thaw cycles. The bases were introduced into the vacuum system via precision leak valves. Amino acids and peptides were dissolved in deionized water and applied to a glycerol matrix on a copper-tipped direct inlet probe.

The pulse sequence used to evaluate reactions contained a series of ejection pulses to isolate the protonated peptide and was presented in the earlier report [14].

\section{Theoretical Model}

Molecular orbital calculations were performed on an Indigo Elan (Silicon Graphics Inc., Mountain View, CA) computer by using the AM1 theoretical model [22, 23] contained in a molecular orbital package called Spartan (Wavefunction Corp., Irvine, CA). The rationale for the choice of theoretical model and discussions of its performance in predicting proton affinities was provided in an earlier publication [23]. The graphics interface feature of this program has been extremely useful for identification of reasonable structures for the global and local minima. All structures are fully opti- 
mized. For each reported structure, several other conformations were analyzed to ensure that a local minimum of a specific proton binding site was found.

\section{Gas-Plase Basicity Scale}

When this work began, the main source of gas-phase basicity values was a compilation by Lias, Liebman and Levin (LLL) [6] of numerous gas-phase studies. Very recently, two other basicity scales have been introduced that redefine the high end (more basic part) of the scale. A GB scale proposed by Moet-Ner and Sieck (MNS) [24] increased the gas-phase basicity assignments of many organic amines that have GB values in the range of the compounds investigated for this report. Another scale presented by Szulejko and McMahon (SM) [25] also reevaluated the high end and produced values closer to the LLL scale, with many of the values supported by high level ab initio calcula- tions. However, the SM basicity scale is not nearly as complete as the LLL basicity scale. There are, for example, only three compounds in the SM tabulation with $G B$ values within the range of the peptides we studied. Furthermore, direct comparison of the absolute values between the SM and the LLL scales produces differences in absolute GB values that are typically less than $1 \mathrm{kcal} / \mathrm{mol}$. For consistency and convenience, therefore, we decided to use the LLL scale exclusively for this report, and all GB values are relative to the LLL scale unless otherwise noted.

\section{Results}

\section{Proton Transfer Reactions}

The presence of rapid or abrupt changes in reactivity is used in this report to assign gas-phase basicity of amino acids and peptides. After the protonated pep-
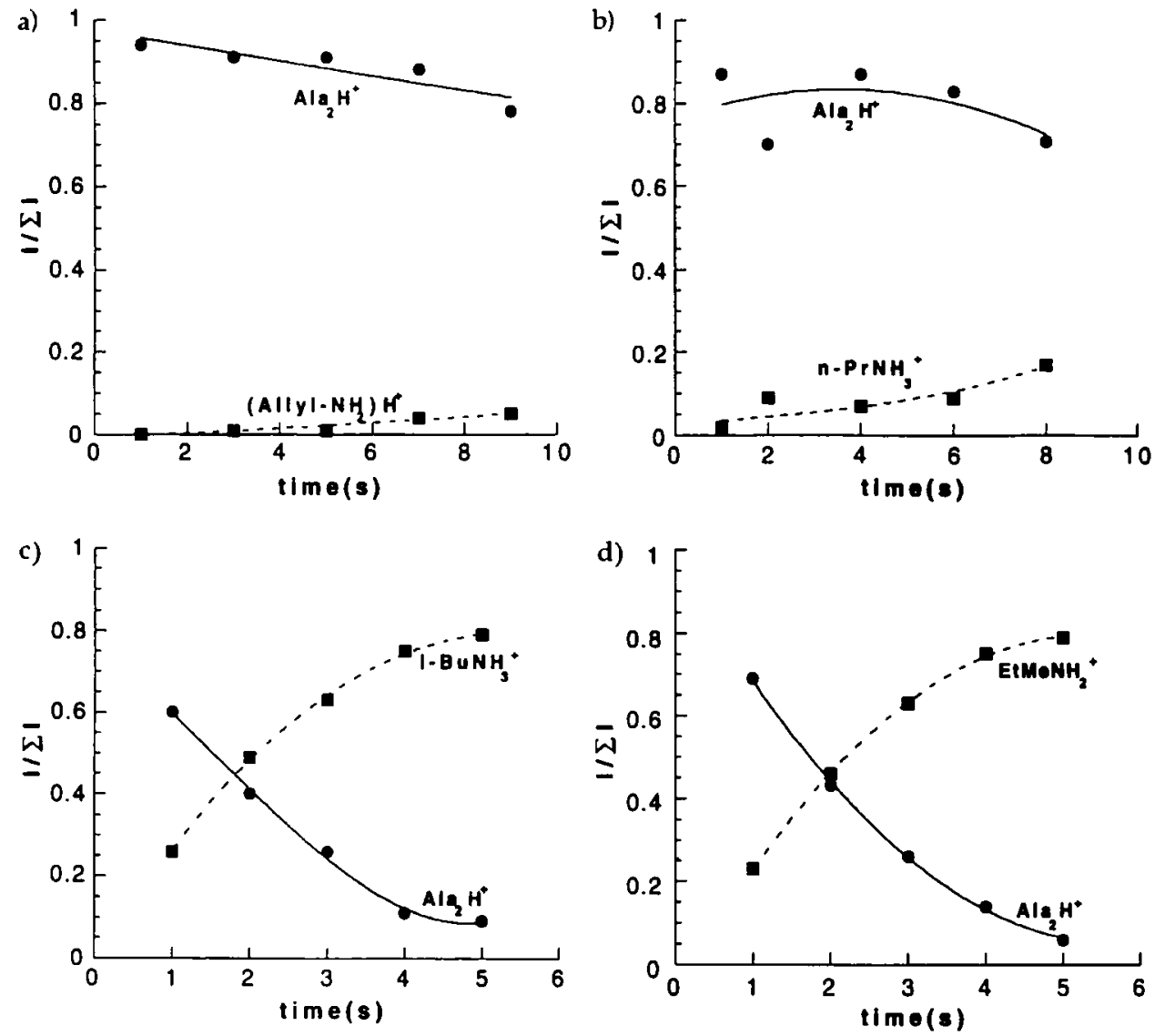

Figure 2. Relative intensity profile of protonated dialanine reacting with (a) allylamine, GB $=207.9$ $\mathrm{kcal} / \mathrm{mol}\left(1.4 \times 10^{-8}\right.$ torr), (b) n-propylamine, $210.1\left(1.3 \times 10^{-\mathrm{s}}\right.$ torr), (c) $i$-butylamine, 211.1 $\left(1.2 \times 10^{-8}\right.$ torr), and (d) ethylmethylamine, $215.1\left(1.1 \times 10^{-8}\right.$ torr). The symbol $I / \sum I$ represents the intensity of the ion over all ion intensities. No reactions or extremely slow reactions are observed in (a) and (b), whereas rapid reactions are observed in (c) and (d). The GB of dialanine therefore lies between the GB of n-propylamine and i-butylamine. 
tide is transferred and isolated in the analyzer cell, it is allowed to undergo proton transfer reactions with the background pressure of a reference base. The behaviors of the relative abundance of a protonated peptide in reaction with four different reference bases (at pressures between 1 and $7 \times 10^{-8}$ torr) of increasing basicity are shown in Figure 2 for dialanine. When the bases are $n$-propylamine (GB $210.1 \mathrm{kcal} / \mathrm{mol}$ ) and allylamine $(207.9 \mathrm{kcal} / \mathrm{mol})$, negligible proton transfer is observed over a period lasting up to $8 \mathrm{~s}$ (Figure $2 \mathrm{a}$ and $\mathrm{b}$ ). Rapid proton transfer is observed over the same period when the bases are $i$-butylamine $(211.1 \mathrm{kcal} / \mathrm{mol})$ and ethylmethylamine $(215.1 \mathrm{kcal} / \mathrm{mol})$. The abrupt change in reactivity between $n$-propylamine and $i$-butylamine, which corresponds to a difference of only $1.0 \mathrm{kcal} / \mathrm{mol}$ change in the GB values, allows simple assignment of the GB of this dipeptide. However, compounds with steric hindrance complicate assignments because their general reactivities are decreased [26]. Alternatively, reaction efficiencies, defined as the ratio $k_{\exp } / k_{\mathrm{ADO}}$, where $k_{\text {exp }}$ is the experimental rate constant and $k_{A D O}$ is the theoretical rate constant obtained from average dipole orientation theory $[27,28]$, provide a more facile indicator of changes in reactivity. Theoretical rate constants are determined from the polarizability and the dipole moment of the reference bases, but do not take into account the structural features of the ions. Polarizabilities are available or can be closely approximated by using the method of Miller [21]. Dipole moments were obtained from the literature or were calculated by using AM1 $[22,23]$. Dipole moments obtained from AM1 were typically within $25 \%$ of the experimental dipole moments and did not significantly affect the value of the theoretical rate constants.

Rate constants were obtained directly from proton transfer reactions (Reaction 2 ) by assuming a pseudofirst-order behavior for the protonated peptides. Derivation and manipulation of the rate equations produces a linear relationship between the expression $\ln \left(1+\left(\mathrm{BH}^{+}\right) /\left(\mathrm{AH}^{+}\right)\right)$and reaction time $(t)$, where $\left(\mathrm{BH}^{+}\right) /\left(\mathrm{AH}^{+}\right)$is the ratio of the abundances of the protonated reference base and peptide, respectively. The slope contains the rate constant of the reaction. The example of the reaction of protonated valine with $s$-butylamine is representative and shows the expected linear behavior $(R=0.992$; Figure 3a).

$$
\mathrm{AH}^{+}+\mathrm{B} \rightarrow \mathrm{BH}^{+}+\mathrm{A}
$$

Dimer formation is often observed when the gasphase basicity of the protonated peptide and the reference base are similar (Reaction 3 ). The presence of the mixed dimer in the spectra produces an additional complication in the rate analysis that is dealt with by using the steady state approximation. Manipulation of the rate equations and plotting with respect to reaction time similarly produce a linear behavior as illustrated by the reaction of protonated trivaline and cyclohex-

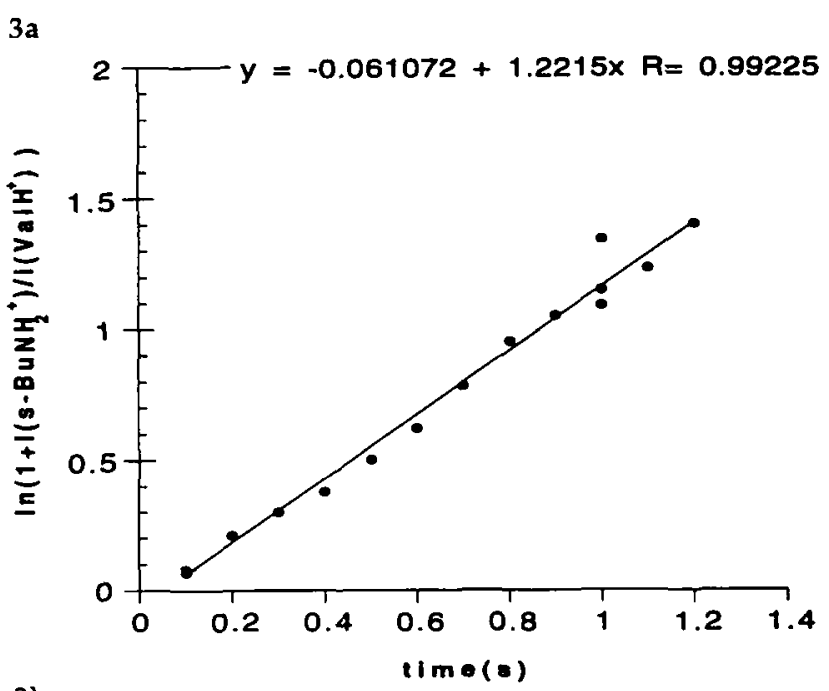

$3 b$

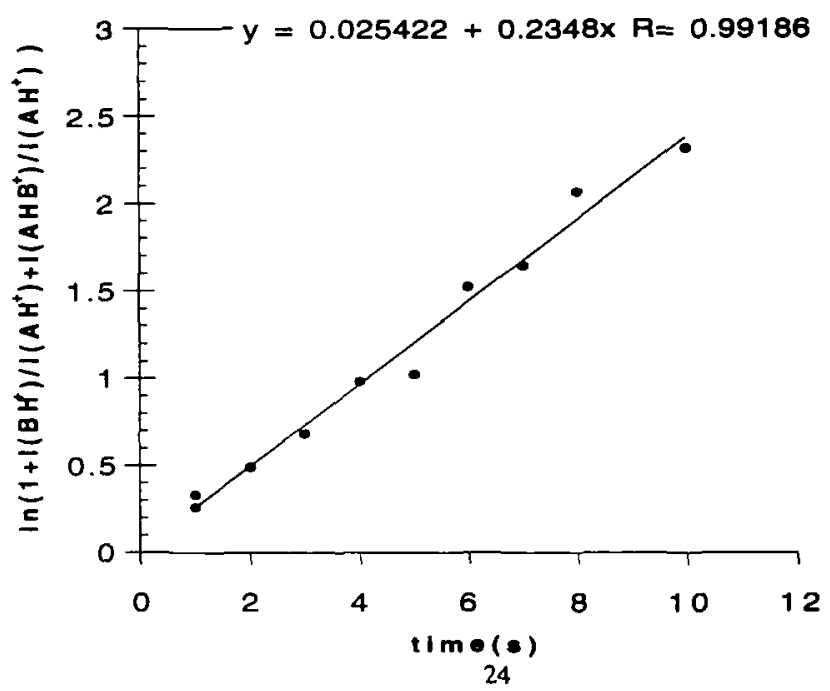

Figure 3. (a) Kinetic plot of direct proton transfer reaction involving protonated valine and s-butylamine. The rate constant is obtained from the slope. (b) Kinetic plot of proton transfer reactions when dimerization is involved for the reaction of protonated trivaline and cyclohexylamine. The rate constant is obtained from the slope.

ylamine $(R=0.992 ;$ Figure $3 b)$.

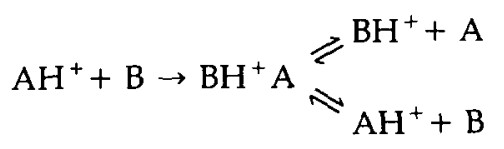

Rate constants (and the reaction efficiencies) for the reactions of protonated oligomers of alanine and valine with selected groups of reference bases are provided in Tables 1 and 2. Reaction efficiencies accurately predict transitions between endergonic and exergonic reactions $[29,30]$. Efficiencies greater than $50 \%$ have been shown to characterize exergonic reactions. The same criterion has been used in this report to assign GB values, that is, a reaction efficiency greater than $50 \%$ indicates that the reference base has a GB value greater 
Table 1. Rate constants $\left(\times 10^{-9} \mathrm{~cm}^{3}\right.$ molecule $\left.{ }^{-1} \mathrm{~s}^{-1}\right)$ and efficiencies (in parentheses) for the reactions of alanine oligomers with selected reference bases

\begin{tabular}{lcccc}
\hline $\begin{array}{l}\text { Reference base } \\
\text { (GB 300 K) }\end{array}$ & Ala & $(\mathrm{Ala})_{2}$ & $(\mathrm{Ala})_{3}$ & (Ala $_{4}$ \\
\hline $\begin{array}{l}\text { Dimethylformamide } \\
(203.6)\end{array}$ & 0.07 & 0.15 & 0.17 & 0.09 \\
3-F-Pyridine & $(3)$ & $(7)$ & $(8)$ & $(5)$ \\
$(206.2)$ & 1.8 & 0.04 & 0.06 & 0.06 \\
Allylamine & $(122)$ & $(3)$ & $(5)$ & $(5)$ \\
$(207.9)$ & 0.64 & 0.03 & 0.03 & 0.09 \\
$n$-Propylamine & $(46)$ & $(2)$ & $(3)$ & $(7)$ \\
$(210.1)$ & 1.2 & 0.07 & 0.12 & 0.20 \\
i-Butylamine & $(90)$ & $(5)$ & $(10)$ & $(18)$ \\
$(211.1)$ & 1.1 & 1.1 & 0.82 & 0.75 \\
$s$-Butylamine & $(76)$ & $(85)$ & $(67)$ & $(61)$ \\
$(211.7)$ & 0.96 & 1.5 & 0.91 & 2.1 \\
$n$-Ethylmethylamine & 1.6 & 1.6 & 0.72 & 0.68 \\
$(215.1)$ & $(116)$ & $(128)$ & $(60)$ & $(58)$ \\
\hline
\end{tabular}

Table 2. Rate constants $\left(\times 10^{-4} \mathrm{~cm}^{3}\right.$ molecule $\left.{ }^{-1} \mathrm{~s}^{-1}\right)$ and efficiencies (in parentheses) for the reactions of valine oligomers with selected reference bases

\begin{tabular}{lcccc}
\hline $\begin{array}{l}\text { Reference base } \\
\text { (GB 300 K) }\end{array}$ & Val & $\left(\mathrm{Val}_{2}\right.$ & $(\mathrm{Val})_{3}$ & $(\mathrm{Val})_{4}$ \\
\hline \hline DMF & 0.09 & & & \\
$(203.6)$ & $(4)$ & & & \\
$\begin{array}{c}\text { c-Propylamine } \\
(206.6)\end{array}$ & 0.03 & & & \\
Allylamine & $(2)$ & & & \\
$(207.9)$ & 0.80 & 0.13 & 0.14 & 0.08 \\
$n$-Propylamine & $(50)$ & $(10)$ & $(11)$ & \\
$(210.1)$ & 1.70 & 0.13 & 0.12 & 0.08 \\
$s$-Butylamine & $(134)$ & $(10)$ & $(11)$ & $(7)$ \\
$(211.7)$ & 0.73 & 0.22 & 0.22 & 0.22 \\
$c$-Hexylamine & $(54)$ & $(19)$ & $(19)$ & $(19)$ \\
$(213.4)$ & 2.10 & 0.49 & 0.55 & 0.41 \\
$n$-Ethylmethylamine & 1.10 & 0.89 & 0.56 & 0.40 \\
$(215.1)$ & $(88)$ & $(89)$ & $(52)$ & $(37)$ \\
Di-ethylamine & 1.20 & 0.99 & 0.55 & 0.36 \\
$(217.7)$ & $(104)$ & $(90)$ & $(52)$ & $(35)$ \\
Di-n-propylamine & 1.30 & 0.89 & 0.80 & 0.55 \\
$(219.7)$ & $(100)$ & $(77)$ & $(73)$ & $(50)$ \\
\hline
\end{tabular}

than the peptide. For example, the efficiencies of protonated alanine reactions show an increase from dimethyl formamide (3\%) to 3-fluoropyridine (100\%). Reactions of protonated alanine with more basic compounds produce rate constants that are consistently at or higher than $50 \%$, with some fluctuations. The GB of alanine is therefore assigned to lie between 203.6 and 206.2, or $204.9 \pm 1.3 \mathrm{kcal} / \mathrm{mol}$. Our assigned value is slightly lower than that reported in the literature, which ranges from 206.6 to $208.6 \mathrm{kcal} / \mathrm{mol}[4,5,7,11]$. The uncertainties listed in Table 3 correspond to the difference between the assigned GB and the GBs of the reference bases that bracket the peptide. One should keep in mind the uncertainties in the GBs of the reference bases when the uncertainty values are used.
The oligomeric peptides (Ala $)_{2},(\mathrm{Ala})_{3}$, and (Ala) $)_{4}$ are all assigned the same GB-210.6 kcal $/ \mathrm{mol}$ - because of the large change in efficiencies when the protonated species are reacted with n-propylamine and $i$-butylamine. For protonated dialanine this corresponds to an increase in efficiency from 5 to $85 \%$. The efficiencies of reactions with protonated dialanine remain consistently high as reference bases with GB greater than $i$-butylamine are used. The increases in the efficiencies of trialanine and tetraalanine with the two bases are not as large, but this is consistent with the general behavior of these larger compounds. The reactivity of trialanine indicates that it does not have a GB greater than dialanine as measured by this technique. This behavior contrasts with the glycine series where triglycine was found to have slightly greater GB than diglycine. The high efficiencies of the reactions of protonated trialanine with both $i$-butylamine and $s$ butylamine, which are only $0.6 \mathrm{kcal} / \mathrm{mol}$ apart, confirm the upper limit of its GB. The reactivity behavior of tetravaline does not differ significantly from either di- or trialanine.

Assignments of the GB of the valine oligomers were performed in a similar manner. Efficiencies of the reactions of protonated valine undergo a large change between cyclopropylamine and allylamine ( 2 and $59 \%$, respectively). The assigned value of $207.2 \mathrm{kcal} / \mathrm{mol}$ is consistent with the range of literature values, which are between 207.4 and $209.2 \mathrm{kcal} / \mathrm{mol}$. Divaline undergoes its largest change in efficiencies between $n$ butylamine $(9 \%)$ and cyclohexylamine $(41 \%)$. This difference in efficiencies is relatively small, but consistent with the apparently poor reactivities of all the valine oligomers (vide supra). The corresponding efficiencies of the reaction of protonated trivaline with these two bases increase from 19 to $50 \%$, whereas for protonated tetravaline the increase is even smaller; the efficiencies change from 17 to $37 \%$. In any case, both trivaline and tetravaline are assigned the same GB as divaline. The reactivity of both peptides appears to increase only slightly with compounds more basic than cyclohexyl amine. The least reactive is clearly tetravaline, where the efficiencies between cyclohexylamine and di-n-propylamine remain between 35 and $50 \%$, despite the difference of $6.3 \mathrm{kcal} / \mathrm{mol}$ between the GB of the two reference bases.

Table 3. Gas-phase basicities of oligomers of glycine, alanine, and valine. Values are referenced by using the LLL basicity scale [6]

\begin{tabular}{lccc}
\hline & \multicolumn{3}{c}{ GB $(\mathrm{kcal} / \mathrm{mol})$} \\
\cline { 2 - 4 }$n$ & $(\mathrm{Gly})_{n}$ & $(\mathrm{Ala})_{n}$ & $(\text { Val })_{n}$ \\
\hline \hline 1 & $203.1 \pm 0.6$ & $204.9 \pm 1.3$ & $207.3 \pm 0.7$ \\
2 & $208.5 \pm 0.6$ & $210.6 \pm 0.5$ & $212.6 \pm 0.8$ \\
3 & $209.6 \pm 0.6$ & $210.6 \pm 0.5$ & $212.6 \pm 0.8$ \\
4 & $209.6 \pm 0.6$ & $210.6 \pm 0.5$ & $212.6 \pm 0.8$ \\
5 & $209.6 \pm 0.6$ & & \\
\hline
\end{tabular}


The GB values of linear glycine oligomers (Gly $n=1-5$ ) have been reported previously by using the MNS basicity scale: large changes observed in the rate constants were used to assign gas-phase basicities (Table 3) [14]. The data have been reevaluated for this report by using reaction efficiencies and the LLL basicity scale. The assigned absolute values of all the glycine oligomeric peptides change slightly with the use of the LLL basicity scale. The use of reaction efficiencies, instead of rate constants alone, does not alter the relative ordering. Earlier we assigned pentaglycine to be slightly more basic than tetraglycine. Reanalysis of the data indicates no observable change in GB between the two peptides.

\section{Effects of Translational Excitation on Proton Transfer Reactions}

Translational excitation is a concern in this technique where ions are produced externally and transferred to the analyzer region of the Fourier transform mass spectrometry instrument. Translational excitation also can be obtained during the ion isolation step, when a series of oscillating electric fields is applied to the analyzer plates with frequencies near the cyclotron frequency of the ion. The effect of this "off-resonance" excitation is particularly strong when the mass-tocharge ratio of the ions to be ejected is near that of the trapped ion. Ion isolation is, however, necessary to minimize proton transfer reactions between the reference base and other protonated species. The net effect of translational excitation is illustrated by the reaction of $i$-butylamine with triglycine (Table 4 ). The mass of triglycine $(m / z 190)$ is close to the mass of the protonated dimer of glycerol $(m / z 185)$; the latter is usually ejected before the proton transfer reactions are allowed to proceed. Under typical experimental conditions

Table 4. The effects of translational excitation on the rate constants

\begin{tabular}{|c|c|c|}
\hline Reactions & $\begin{array}{l}\text { Reaction } \\
\text { conditions }\end{array}$ & $\begin{array}{c}\text { Rates }\left(\mathrm{cm}^{3}\right. \\
\text { molecule } \\
\left.-1 \mathrm{~s}^{-1}\right)\end{array}$ \\
\hline \multirow[t]{5}{*}{$\begin{array}{l}{\left[(\mathrm{G} \mid \mathrm{y})_{3}+\mathrm{H}^{!}\right]} \\
(\mathrm{m} / \mathrm{z} 190) \\
\text { with i-butylamine }\end{array}$} & $\begin{array}{l}\text { Ejection } 185, V_{p p} \\
=4.0 \mathrm{~V} \\
\text { with pulse of } \mathrm{N}_{2}\end{array}$ & $1.6 \times 10^{-9}$ \\
\hline & $\begin{array}{l}\text { Ejection } 185, V_{\rho p} \\
\quad=4.0 \mathrm{~V}\end{array}$ & $1.4 \times 10^{9}$ \\
\hline & $\begin{array}{l}\text { Ejection } 185, V_{p p} \\
=7.6 \mathrm{~V}\end{array}$ & $1.1 \times 10^{-9}$ \\
\hline & $\begin{array}{l}\text { Ejection } 185, V_{p p} \\
=12 \mathrm{~V}\end{array}$ & $9.0 \times 10^{-10}$ \\
\hline & $\begin{array}{l}\text { Ejection } 185, V_{p p} \\
=15.5 \mathrm{~V}\end{array}$ & $6.8 \times 10^{-10}$ \\
\hline \multirow{2}{*}{$\begin{array}{l}{\left[(\mathrm{G} \mid \mathrm{y})_{4}+\mathrm{H}^{+}\right]} \\
(\mathrm{m} / z 247) \\
\text { with } n \text { propylamine }\end{array}$} & $\begin{array}{l}\text { Ejection 185, } V_{\mathrm{pp}} \\
=13 \mathrm{~V}\end{array}$ & $0.44 \times 10^{-9}$ \\
\hline & $\begin{array}{l}\text { Ejection } 185, V_{p p} \\
\quad=42 \mathrm{~V}\end{array}$ & $0.39 \times 10^{-9}$ \\
\hline
\end{tabular}

(ejection pulse $10 \mathrm{~ms}$, amplitude of $4.0 \mathrm{~V}$ peak to peak) a rate of $1.4 \times 10^{\circ 9} \mathrm{~cm}^{3}$ molecule ${ }^{1} \mathrm{~s}^{-1}$ is obtained. Pulsing nitrogen gas into the analyzer chamber after ion isolation increases the rate of the reaction to $1.6 \times$ $10^{-4} \mathrm{~cm}^{3}$ molecule ${ }^{1} \mathrm{~s}$ '. We commonly observe that translationally excited ions have slower reaction rates. For example, increasing the amplitude of the ejection pulse to $7.6 \mathrm{~V} p-p$ decreases the reaction rate to $1.1 \times 10^{-4} \mathrm{~cm}^{3}$ molecule ${ }^{-1} \mathrm{~s}$ '. Increasing the amplitude further to $15.5 \mathrm{~V}$ decreases the rate constant to as low as $6.8 \times 10^{10} \mathrm{~cm}^{3}$ molecule ${ }^{1} \mathrm{~s}$ !. When the ejection pulse is further away, as in experiments that involve tetraglycine and $n$-propylamine, the effect of ejection pulses is diminished (Table 4). For example, an increase in the amplitude by over a factor of 3 (from 13 to $42 \mathrm{~V} \mathrm{p-p)} \mathrm{does} \mathrm{not} \mathrm{significantly} \mathrm{decrease} \mathrm{the}$ rates.

Translational excitation can make a compound appear more basic because it decreases the overall rate of the reaction. A stronger base would be needed to observe proton transfer reactions, but would increase the assigned GB value. However, under these experimental conditions, we find that translational excitation, at least that due to off-resonance excitation during ion ejection, can be minimized and does not appear to interfere with the assignment of the GB.

\section{AM1 Calculations of Triglycine and Trialanine}

Molecular orbital calculations have been performed to evaluate the protonated structures of triglycine and trialanine. Earlier we [14] reported the results of AM1 calculations performed on protonated diglycine. The qualitative results recently have been supported by high level ab initio calculations [15]. Both sets of calculations predict that the terminal amine is the most favorable site of protonation in both glycine and diglycine. Previously, we reported that the lowest energy structure for protonated diglycine involved hydrogen bonding interaction between the carbonyl group amide and the protonated terminal amine (Structure 1a). The results from ab initio calculations suggest a structure with hydrogen bonding interactions between the terminal amine and both carbonyl amide and carboxylic acid groups that is only 0.47 $\mathrm{kcal} / \mathrm{mol}$ less stable [15]. Further search of the AM1 hypersurface produces a similar type of interaction. Structure $1 \mathrm{~b}$ shows distances of 2.498 and $2.106 \AA$ between the terminal amine and the two respective groups. The $\mathrm{ab}$ initio calculations produced a more symmetrical interaction with distances of 2.291 and $2.247 \AA$, respectively. The new structure $1 \mathrm{~b}$ is, however, lower than $1 \mathrm{a}$ by $5.2 \mathrm{kcal} / \mathrm{mol}$.

Structures $\mathbf{2 a}-\mathbf{f}$ are the most stable protonated conformers of triglycine. These structures were chosen because they represent various protonation sites on the tripeptides. For example, Structure $\mathbf{2 a}$ involves protonation on the terminal amine with hydrogen bonding 


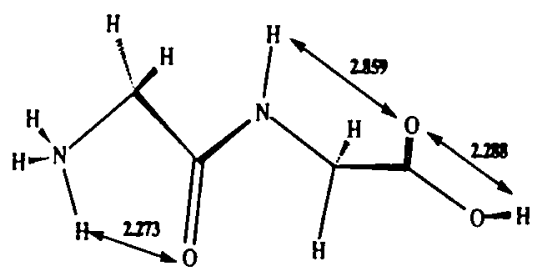

$1 \mathbf{8}$

$\Delta H_{\mathrm{r}}=22.8 \mathrm{kcaV} / \mathrm{mol}$

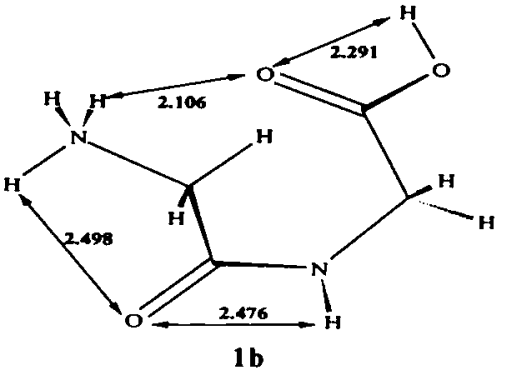

$\Delta H_{t}=17.6 \mathrm{kcal} / \mathrm{mol}$
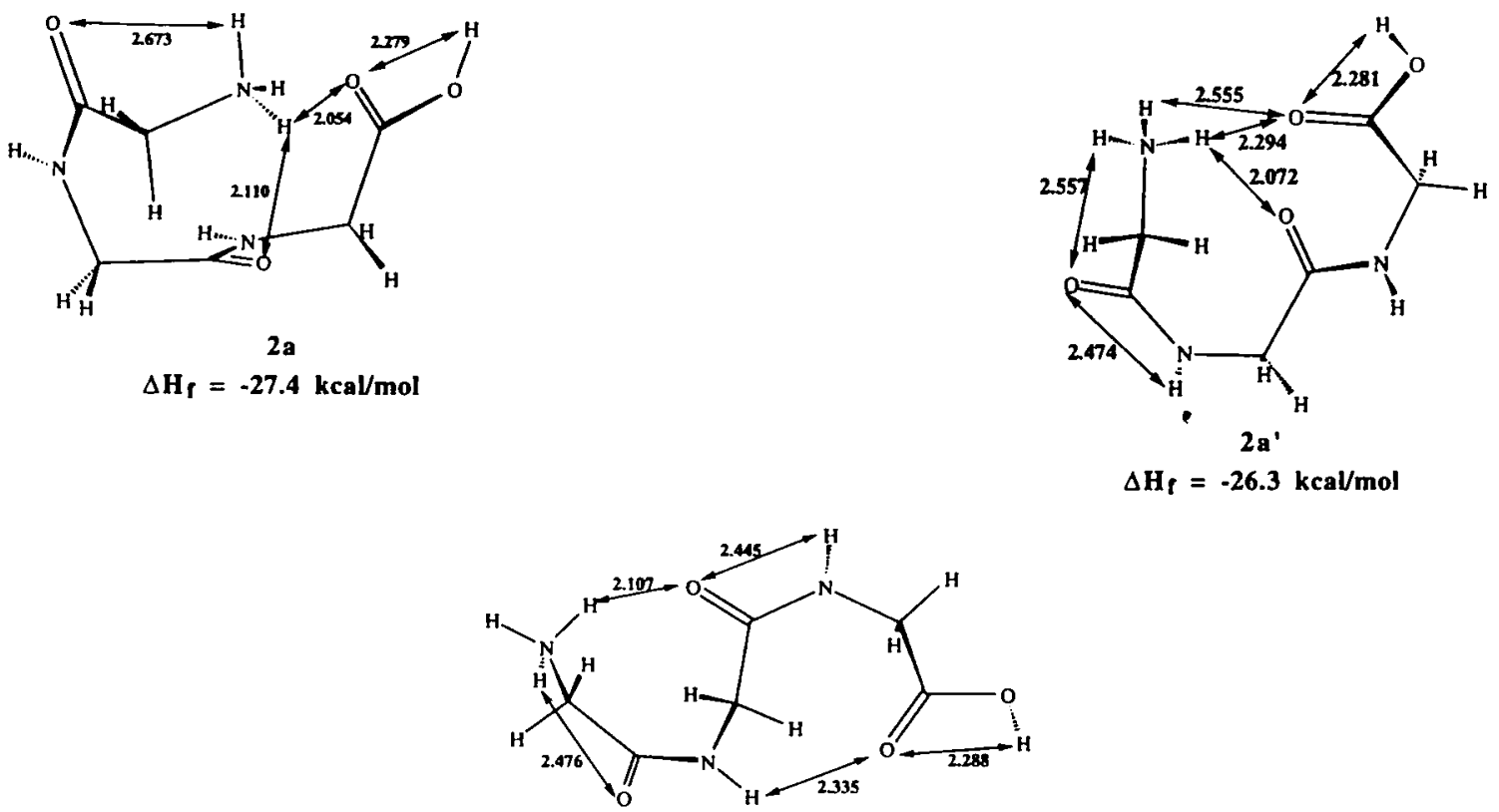

2a'"

$\Delta H_{\mathrm{f}}=-23.1 \mathrm{kcal} / \mathrm{mol}$

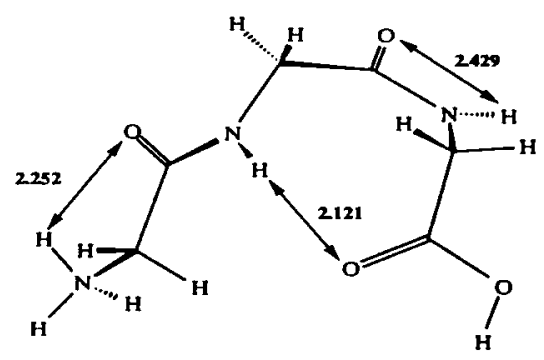

2b

$\Delta H_{\mathrm{f}}=-17.5 \mathrm{kcal} / \mathrm{mol}$

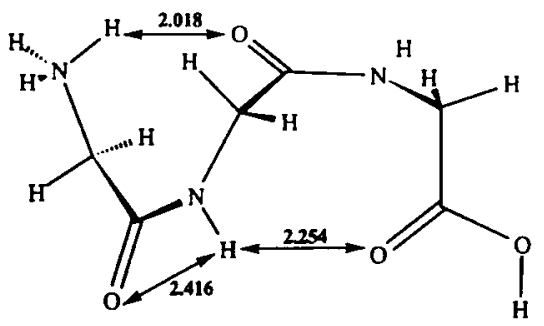

$2 c$

$\Delta H_{\mathrm{r}}=-16.7 \mathrm{kcal} / \mathrm{mol}$

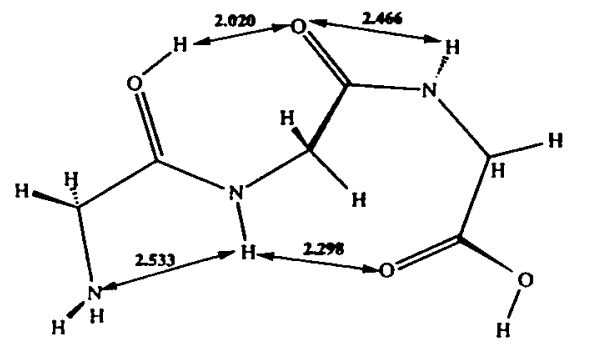

2d

$\Delta H_{\mathrm{r}}=-21.5 \mathrm{kcal} / \mathrm{mol}$

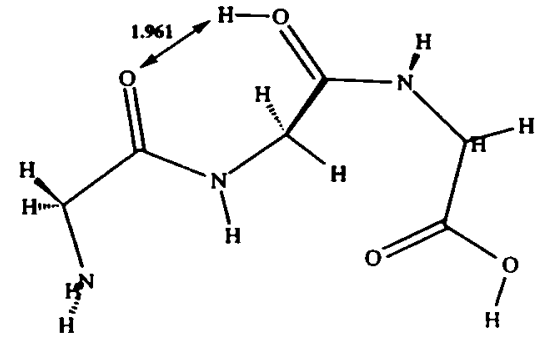

$2 \mathrm{e}$

$\Delta H_{\mathrm{f}}=-15.4 \mathrm{kcal} / \mathrm{mol}$

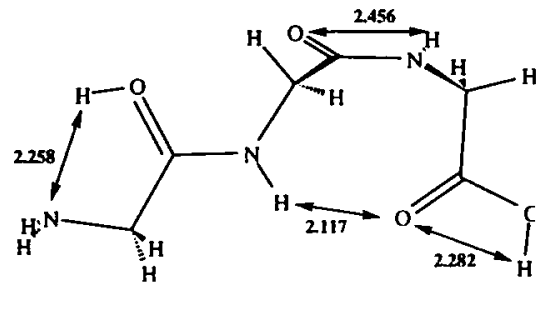

28

$\Delta H_{I}=-16.6 \mathrm{kcal} / \mathrm{mol}$ 
to the three carbonyl groups, whereas Structure 2b involves hydrogen bonding between the terminal amine and the nearest carbonyl amide, and so forth. Hydrogen bonding interactions, often characterized by distances of less than $2.6 \AA$ between the hydrogen and interacting heteroatom (e.g., oxygen and nitrogen) are labeled by their distances. For every structure shown, several other conformers were investigated but not included for having higher relative heats of formation. The lowest energy structure (2a) involves protonation on the terminal amine with extensive intramolecular hydrogen bonding interaction to possibly all three carbonyl groups. The $\mathrm{N}-\mathrm{H} \cdots \mathrm{O}=\mathrm{C}$ bond distances are $2.673,2.110$, and $2.054 \AA$ between the hydrogen on the terminal amine and the oxygen on the three carbonyl groups. Other hydrogen bonding interactions also occur in the molecule, producing further stabilization including the interaction within carboxylic acid that forces this group to be cis-planar with respect to the $\mathrm{CO}-\mathrm{O}$ bond $(\mathrm{CO} \cdots \mathrm{H}-\mathrm{O}$ distance of $2.281 \AA$ ). Conformational microvariations also are observed in the AM1 calculations, even with peptides as small as triglycine. For example, a conformation similar to $2 a$ exists $\left(2 a^{\prime}\right)$ that has the same number and type of H-bonding interactions but is $1.1 \mathrm{kcal} / \mathrm{mol} \mathrm{higher} \mathrm{in}$ energy and contains different hydrogen bond distances for the same interacting atoms. These structures further illustrate the difficulty in finding the global minima in molecules with extensive hydrogen bonding interactions.

The other structures with protonated $\mathrm{N}$-termini indicate that maximizing hydrogen bonding of the amino group with all the carbonyl groups generally provides the most favorable interaction. For example, when the carboxylic acid group does not interact with the protonated $\mathrm{N}$-terminus but instead with a neighboring carbonyl amide hydrogen (Structure 2a"), the heat of formation is slightly higher by $4.3 \mathrm{kcal} / \mathrm{mol}$. When only one carbonyl amide is involved in coordinating with the protonated terminal amine ( $2 b$ and $2 c$ ), the heat of formation increases by about $10 \mathrm{kcal} / \mathrm{mol}$ relative to the most stable structure. There is little difference energetically when interaction occurs with either the neighboring carbonyl group ( $2 b$ ) or one amino acid unit away (2c).

The most stable carbonyl protonated structure corresponds to $\mathbf{2 d}$, where the two carbonyl oxygens of the amides are linked by hydrogen bonding. This species is only $5.9 \mathrm{kcal} / \mathrm{mol}$ less stable than 2a. Extensive hydrogen bonding is also present in $2 \mathrm{~d}$, particularly between the first amide hydrogen and both the terminal amine and the acid carbonyl oxygen ( 2.533 and $2.298 \AA$, respectively). There appears to be a specific preference, on the AM1 surface, for the first carbonyl amide as the site of protonation; the second is less favored by $6.1 \mathrm{kcal} / \mathrm{mol}(\mathbf{2 d}$ and $2 \mathrm{e}$ ). This is somewhat unexpected because both carbonyl groups should have similar proton affinities.

Protonated trialanine structures analogous to the protonated triglycine structures are found on the AM1 surface. To facilitate direct comparisons between the two sets, trialanine structures, which are closely analogous to triglycine structures in terms of protonation sites and intramolecular interactions, are given the same letter designation. The trialanine analog (Structure 3a) of the lowest energy protonated triglycine structure (2a) is also the most stable protonated trialanine structure. Extensive hydrogen bonding between the protonated amine and the three carbonyl groups is evident from the $\mathrm{N}-\mathrm{H} \cdots \mathrm{O}=\mathrm{C}$ distances of 2.606, 2.111 , and $2.065 \AA$. Steric interactions due to the presence of the methyl groups do not appear to prevent hydrogen bonding interactions in this protonated structure. Instead, the alkyl groups are projected radially from the site of protonation, minimizing steric interactions. As with the protonated triglycine, we find conformers with similar energies that utilize the same combination of interactions. For example, $\mathbf{3 a "}$ is also a local minimum analogous to $2 \mathrm{a}^{\prime \prime}$. However, the difference between $3 a^{\prime \prime}$ and $3 a$ is $7.4 \mathrm{kcal} / \mathrm{mol}$ compared to $4.3 \mathrm{kcal} / \mathrm{mol}$ between $2 \mathrm{a}^{\prime \prime}$ and $2 \mathbf{a}$. The structures $\mathbf{2 b}$ and $2 c$ also have analogs in trialanine as $\mathbf{3 b}$ and $\mathbf{3 c}$, respectively. The difference in the heat of formation between $3 \mathbf{b}$ and $3 \mathbf{a}(12.3 \mathrm{kcal} / \mathrm{mol})$ is again slightly larger than the difference between $\mathbf{2 b}$ and $2 \mathbf{a}(9.9$ $\mathrm{kcal} / \mathrm{mol}$ ). There is evidently greater steric interaction in $3 \mathrm{c}$ because it is $17.8 \mathrm{kcal} / \mathrm{mol}$ less stable than 3a compared to $10.7 \mathrm{kcal} / \mathrm{mol}$ for $2 \mathrm{c}$ relative to $2 \mathbf{a}$. Several attempts were made to locate a more stable structure for $3 c$; however, steric interactions appear to prevent hydrogen bonding interactions between the amide $\mathrm{N}-\mathrm{H}$ group and the carboxylic acid group as in $2 \mathrm{c}$. In general we find that the difference in the heats of formation between $3 \mathbf{a}$ and $3 \mathbf{b}-\mathbf{f}$ is greater than between $2 \mathbf{a}$ and $\mathbf{2 b}-\mathbf{f}$. This may be the result of steric interactions in structures $3 \mathbf{b}-\mathbf{f}$ that destabilize these structures relative to $3 a$. It is likely that the differences would be further increased by the presence of larger alkyl groups such as isopropyl (in valine).

Protonation of the carbonyl amide remains unfavorable compared to protonation on the terminal amine. The structure $3 \mathrm{~d}$ is less stable than $3 \mathrm{a}$ by $8.5 \mathrm{kcal} / \mathrm{mol}$ compared to 5.9 for triglycine. Other structures where the carbonyl amides are protonated (e.g., $3 \mathbf{e}$ and $3 \mathrm{f}$ ) are similarly unstable relative to $3 \mathbf{a}$.

\section{Discussion}

All three series show an increase of GB values between the amino acid and the dipeptide (see Figure 4). A slight increase is further observed between di- and triglycine that is not observed in the alanine and valine series. The contributions of intramolecular interactions in the dipeptide appear constant. For the three oligomers this means a similar increase in GB between the amino acid and the dipeptide that corresponds to $5.4,5.7$, and $5.3 \mathrm{kcal} / \mathrm{mol}$ for glycine, alanine, and valine, respectively. An increase of the basicity of diva- 


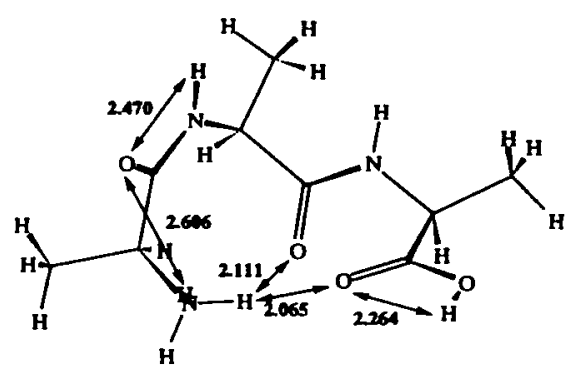

3a

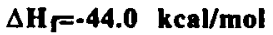

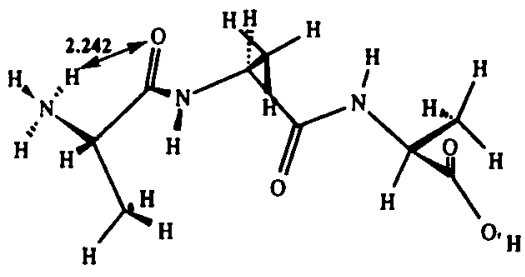

3b

$\Delta H_{\text {fr-31.7 } \mathrm{kcal} / \mathrm{mol}}$

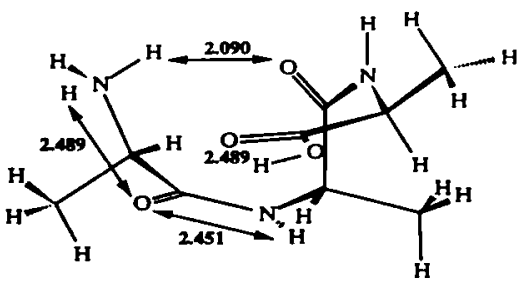

$3 a^{\prime \prime}$

$\Delta \mathrm{Hr}=-36.6 \mathrm{kcal} / \mathrm{mol}$

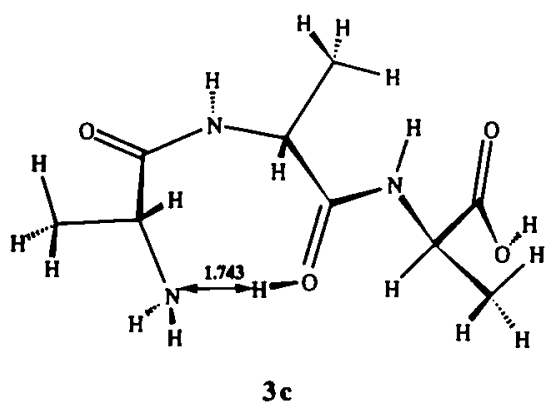

$\Delta H_{\mathrm{r}}=-26.2 \mathrm{kcal} / \mathrm{mol}$

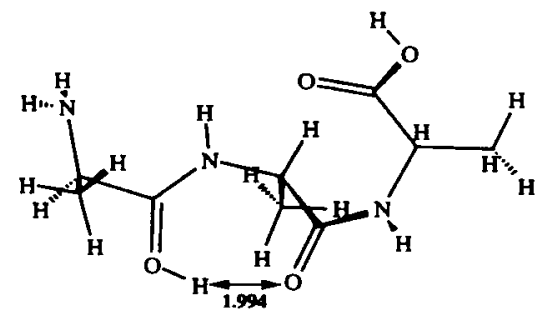

3d

$\Delta \mathrm{H}_{\mathrm{r}}=-35.5 \mathrm{kcal} / \mathrm{mol}$

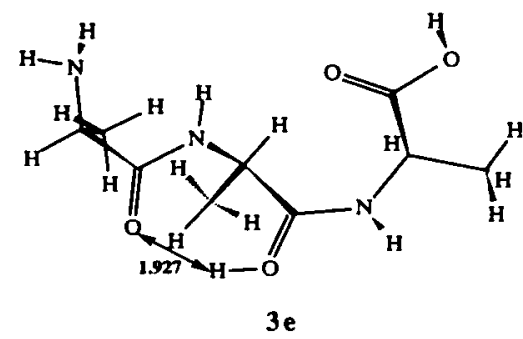

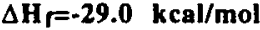

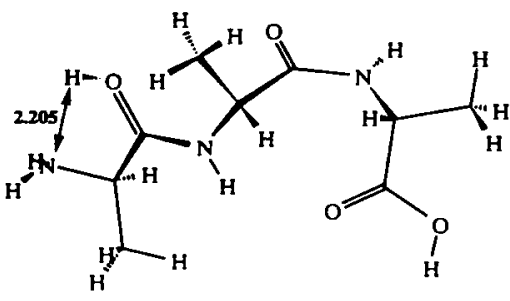

3f

$\Delta H_{f=-29.7} \mathrm{kcal} / \mathrm{mol}$

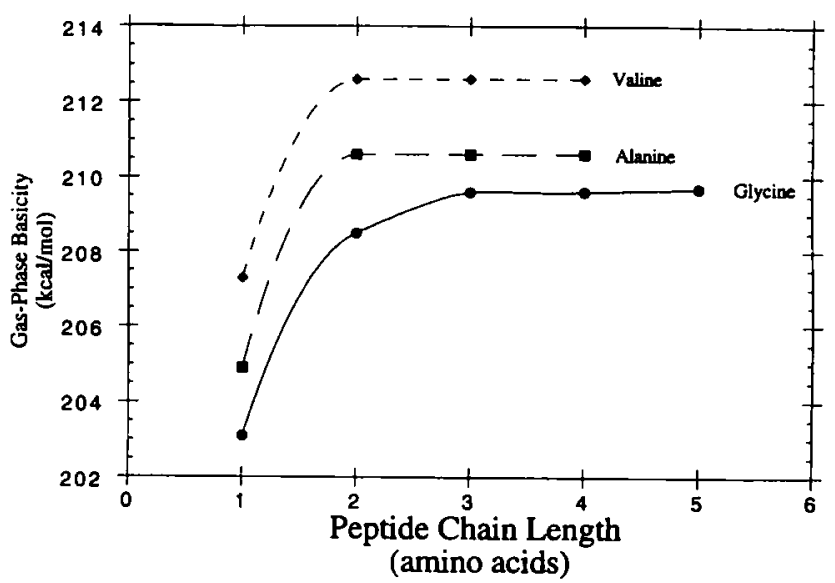

Figure 4. Plot of gas-phase basicity, assigned from bracketing measurements, versus peptide length for oligomers of glycine, alanine, and valine. The curve for each oligomeric series is shifted according to the difference in GB of the amino acids. line is consistent with observations reported by Gorman and Amster [16], who report a $2.5-\mathrm{kcal} / \mathrm{mol}$ difference between the two compounds. We observe a higher increase, which is not unreasonable considering the error limits presented in this and the other authors' work.

The gas-phase basicity of the dipeptide and its relative value compared to the amino acid is consistent with the intramolecular interactions depicted in 1a and 1b. The presence of two interacting base sites is reminiscent of the protonated dimers that have been studied [31]. In other words, a dipeptide can be seen as a protonated amine solvated by a carboxylic acid or any other carbonyl group that contains compounds. Linear correlations between proton affinities and hydrogen bond strength have been proposed [31] specifically for binding of protonated amines with several other functional groups. For the dimers, the correlation follows the relationship

$$
\Delta H_{\mathrm{D}}^{\circ}=\Delta H_{\mathrm{D}}^{\circ}(0)-b \Delta \mathrm{PA}
$$


For $-\mathrm{NH}^{+} \cdots \mathrm{O}$ - bonds $\Delta H^{\circ}{ }_{\mathrm{v}}(0)=30 \pm 2$ and the slope $b=0.26$. Maximum binding occurs when the proton affinity difference ( $\triangle \mathrm{PA})$ is zero. For methylamine and a carboxylic acid the average value is about $20 \mathrm{kcal} / \mathrm{mol}$. If an estimate for entropy is included, that is, the entropy of formation of an eightmembered ring from cyclooctane, the expected $\Delta G$ would be $9 \mathrm{kcal} / \mathrm{mol}$ - not too different from the increase of $5.4 \mathrm{kcal} / \mathrm{mol}$ observed between glycine and diglycine. Correlation of proton affinity differences also would explain the identical increase in GB between the amino acid and the dipeptide for the three series, that is, in all three the $\triangle P A$ contribution should be similar.

The difference in GB between diglycine and triglycine, though small, is supported by experiments performed by other groups [13, 15]. The results of molecular orbital (MO) calculations that involve the triglycine and trialanine further support this behavior and suggest that the increase in the experimental GB should be even greater than that observed. The structures $\mathbf{2 b}$ and $2 \mathbf{c}$ of protonated triglycine are analogous to the most stable structure of diglycine (1a) and share the primary interactions found in the dipeptide. There appears to be little difference between the interaction of the protonated terminal amine with either the first or second amide group because the energy difference between $2 \mathrm{~b}$ and $2 \mathrm{c}$ is only $0.8 \mathrm{kcal} / \mathrm{mol}$. However, the additional hydrogen bonding interaction provided by the second amide group makes $2 \mathbf{a}$ about $10 \mathrm{kcal} / \mathrm{mol}$ more stable than either $\mathbf{2 b}$ or $\mathbf{2 c}$. The additional stabilization would be consistent with a greater proton affinity $(-\Delta H)$ for the tripeptide than the dipeptide. The increase in $G B(-\Delta G)$ obtained experimentally $(1.1 \mathrm{kcal} / \mathrm{mol})$ is comparatively small. The comparison of $\mathrm{MO}$ calculations of triglycine and trialanine suggests that a similar increase in proton affinity also should be present in the trialanine and the trivaline series. The lowest structures found in both sets of calculations (2a and $3 a$ ) are similar because the methyl groups of trialanine do not appear to disrupt the intramolecular hydrogen bonding interactions. Experimental GB values, however, do not exhibit this behavior. The GB values of trialanine and trivaline are not observed to increase relative to the respective dipeptides.

The small increase in the GB of triglycine relative to the dipeptide and the absence of similar increases in trialanine and trivaline is possible if the net change in the entropy is negative. $\mathrm{MO}$ calculations suggest a high degree of ordering due to the interaction of the carbonyl groups with the protonated terminal amine. Furthermore, experimental deviation in this method of assigning GB values may not readily allow observation of small increases in trialanine and trivaline. In this regard, bracketing experiments that use equilibrium reactions would be more accurate than the kinetic reactions used here, but are not possible because a background pressure of neutral peptide would not be sustainable. It is not likely that translational excitation would be the reason for the apparent lack of a large
GB increase in the tripeptide. An increased translational energy, as we have shown, would actually increase the apparent $G B$, slowing the rate and requiring stronger bases to produce proton transfer reactions.

A high degree of ordering of the carbonyl groups presents a situation not unlike those found in the gas-phase solvation of ions or the formation of gasphase ionic clusters [32]. The carbonyl groups in these small peptides could act in the same manner as the inner solvation shell of the solvated ions. Moet-Ner has recently shown that alkylation does not affect the inner shell binding energies in protons solvated by amines and alcohols [32]. These results are consistent with the lack of a destabilizing effect of the alkyl groups on the most stable structures of protonated peptides. The alkyl groups in dialanine and divaline are positioned to allow intramolecular interactions similar to those found in diglycine. In protonated trialanine, the other protonated structures appear to be destabilized relative to the most stable structure (e.g., compare $3 a$ and $3 a^{\prime \prime}$ ). This indicates that steric interactions play a greater role in destabilizing some structures and slightly favor the most stable structure.

The most readily observed affect of the alkyl groups is their interference in proton transfer reactions. This is readily observed with the oligomers of valine and, to a lesser extent, the oligomers of alanine. Proton transfer reactions that involve divaline do not produce efficiencies of $100 \%$ with the reference bases chosen for this study. The efficiencies of analogous reactions that involve trivaline and tetravaline are lower. For protonated tetravaline, reaction efficiencies remain at or below $50 \%$ despite relatively large changes in GBs. These consistently low reaction efficiencies make assignment of the $G B$ values for these compounds less accurate. For tri- and tetravaline, the GB values should at least be as large as divaline. There are no apparent intramolecular interactions observed in the MO calculation of triglycine and trialanine to suggest significant destabilization in the protonated tri- and tetravaline structures.

In general, steric interactions between the protonated peptide and the reference neutral base will create problems in the determination of gas-phase basicities of still larger peptides. The ability of alkyl group interactions to slow proton or hydride transfer reactions has been well established [33]. Steric interactions at or near the site of protonation are already known to significantly decrease the rates of even highly exergonic reactions [26]. These experiments, however, involve molecules where the protonation sites are blocked directly. For example, the reactivity of protonated pyridinium compounds is significantly decreased by the presence of large alkyl groups on the ortho positions. In contrast, with protonated peptides steric interactions are the result of ordering and not of primary structural effects. The protonation sites are blocked by the ordering of the alkyl groups that results from the ordering of the carbonyl groups as the latter 
try to maximize interactions with the protonated amine group. This behavior is supported by MO calculations that predict that the most stable arrangement for protonated trialanine is structure $\mathbf{3 a}$. The radial arrangement of the methyl groups in protonated trialanine appears to partially shield the site of protonation from approach by a neutral base. This effective shielding would greatly increase with amino acids that have larger alkyl groups such as valine and leucine. The problem for those measuring gas-phase basicity becomes particularly acute when the bases necessary for deprotonation are themselves sterically hindered, such as dialkyl amines or alkyl amines with large alkyl groups such as cyclohexyl and s-butyl, and even $t$ butylamines.

\section{Acknowledgments}

Funding was provided by the National Science Foundation (CHE-9310092). The computers for performing MO calculations were provided by the Department of Chemistry, U.C. Davis.

\section{References}

1. Hipple, P. H. V.; Schleich, T. Acc. Chem. Res. 1969, 2, 257-265.

2. Robinson, D. R.; Jencks, W. P. J. Am. Chem. Soc. 1965, 87, 2470-2479.

3. Flanagan, M. A.; Ackers, G. K.; Matthew, J. B.; Hanania, G. I. H.; Gurd, F. R. N. Biochemistry 1981, 20, 4739-4744.

4. Locke, M. J.; Hunter, R. L.; Mclver, R. T., Jr. J. Am. Chem. Soc. 1979, 101, 272-273.

5. Locke, M. J.; McIver, R. T., Jr. /. Am. Chem. Soc. 1983, 105, 4226-4232.

6. Lias, S. G.; Liebman, J. F.; Levin, R. D. J. Phys. Chem. Ref. Data 1984, 13, 695-808.

7. Moet-Ner, M.; Hunter, E. P.; Field, F. H. J. Am. Chem. Soc. 1979, 101, 686-689.

8. Isa, K.; Omote, T.; Amaya, M. Org. Mass Spectrom. 1990, 25 , 620-628.
9. Kinser, R. D.; Ridge, D. P.; Uggerud, E. Proceedings of the American Society for Mass Spectrometry; Nashville, TN, May 19-24, 1991.

10. Bojesen, G. J. Am. Chem. Soc. 1987, 109, 5557-5558.

11. Gorman, G. S.; Speir, J. P.; Turner, C. A.; Amster, I. J. J. Am. Chem. Soc. 1992, 114, 3986-3988.

12. Bojesen, G. J. Chem. Soc. Chem. Commun 1986, 244-245.

13. Wu, Z.; Fenselau, C. J. Am. Soc. Mass Spectrom. 1992, 3, 863-866.

14. Wu, J.; Lebrilla, C. B. J. Am. Chem. Soc. 1993, 115, 3270-3275.

15. Zhang, K.; Zimmerman, D. M.; Chung-Phillips, A.; Cassady, C. J. J. Am. Chem. Soc. 1993, 115, 10812-10822.

16. Gorman, G. S.; Amster, I. J. J. Am. Chem. Soc. 1993, 115, $5729-5735$.

17. Burger, K. Biocoordination Chemistry: Coordination Equilibria in Biologically Active Systems; Ellis Horwood: London, 1990.

18. Carroll, J. A.; Ngoka, L.; McCullough, S. M.; Gard, E.; Jones, A. D.; Lebrilla, C. B. Anal. Chem. 1991, 63, 2526-2529.

19. McCullough, S. M.; Gard, E.; Lebrilla, C. B. Int. J. Mass Spectrom. Ion Processes 1991, 107, 91-102.

20. Bartmess, J. E.; Georgiadis, R. M. Vacuum 1983, 33, 149-153.

21. Miller, K. J. J. Am. Chent. Soc. 1990, 112, 8533-8542.

22. Dewar, M. J. S.; Zoebisch, E. G.; Healy, E. F.; Stewart, J. J. P. J. Am. Chem. Soc. 1985, 107, 3902-3909.

23. Dewar, M. J. S.; Dieter, K. M. J. Am. Chem. Soc, 1986, 108, 8075-8086.

24. Moet-Ner, M.; Sieck, L. W. J. Am. Chem. Soc. 1991, 113, $4448-4460$.

25. Szulejko, J. E.; McMahon, T. B. I. Am. Chem. Soc. 1993, 115, 7839-7848.

26. Moet-Ner, M.; Smith, S. J. Am. Chem. Soc. 1991, 113, 862-869.

27. Su, T.; Bowers, M. T. J. Chem. Phys. 1973, 58, 3027-3037.

28. Su, T.; Bowers, M. T. Int. I. Mass Spectrom. Ion Phys. 1973, 12 , 347-356.

29. Bohme, D. K.; MacKay, G. I.; Schiff, H. I. J. Chem. Phys. 1980, $73,4976-4986$.

30. Büker, H. H.; Grützmacher, H. F. Int. J. Mass Spectrom. Ion Processes 1991, 109, 95-104.

31. Meot-Ner, M. J. Am. Chem. Soc. 1984, 106, 1257-1264.

32. Meot-Ner, M. J. Am. Chem. Soc. 1992, 114, 3312-3322.

33. Sunner, J.; Hirao, K.; Kebarle, P. J. Phys. Chem. 1989, 93, 4010-4016. 